\title{
ANNOTATIONS
}

\section{Myopia and School Work}

The notice of the report of the Medical Officer of the London County Council (p. 664) upon the work of his department in the schools is of interest, mainly because of the observations made upon the children who are admitted to the "Myope Classes." It will be remembered that these children suffer from high degrees of myopia; nothing under five or six dioptres is deemed fit for admission. This may have some bearing upon the observations that there is amongst them on admission a higher average of under nourishment than with normal school children. How can a child that cannot see with ease get the exercise and therewith the robustness of the normal? It has been established that the appearance of under nourishment is not always due to lack of food. This is a point that might well be determined with regard to these children.

But the abstract is of interest because it illustrates well the work that is being done by the school medical officers throughout the country. Too often we are inclined to look upon this work as " routine" and therefore devoid of interest. But to the open-eyed school doctor there are always points of exceptional interest arising which require investigation. The reports of the chief school doctor of the several education committees throughout the country abound in reports of investigations that have been made during the year. A list of these investigations is given in the Annual Report of the Chief Medical Officer of the Board of Education. Some of these investigations deal with eye matters. It would be of interest if our readers followed the example of Dr. Sourasky and sent the Editor of this Journal notes upon any observations of interest that appear in the reports of their local authorities.

\section{William Mackenzie Medal}

Ophthalmologists recently paid honour to the memory of one of the fathers of British Ophthalmology by establishing a William Mackenzie Memorial Fund, one of the purposes of which is the recognition and encouragement of original work in our speciality.

William Mackenzie was a Glasgow man and his professional life was spent in that city. The memorial fund will be in the hands of 
the governing body of the Glasgow Eye Infirmary.! The committee, appointed periodically to deal with the expenditure of the income of the fund, and with the award of the Mackenzie Medal, contains representatives of the Eye Infirmary, The Royal Faculty of Physicians and Surgeons, and the University of Glasgow, with all of which institutions William Mackenzie was associated during his life-time.

It is perhaps fitting that the first award of the William Mackenzie Medal should have been made to Dr. A. Maitland Ramsay, formerly of Glasgow, one of Mackenzie's successors on the

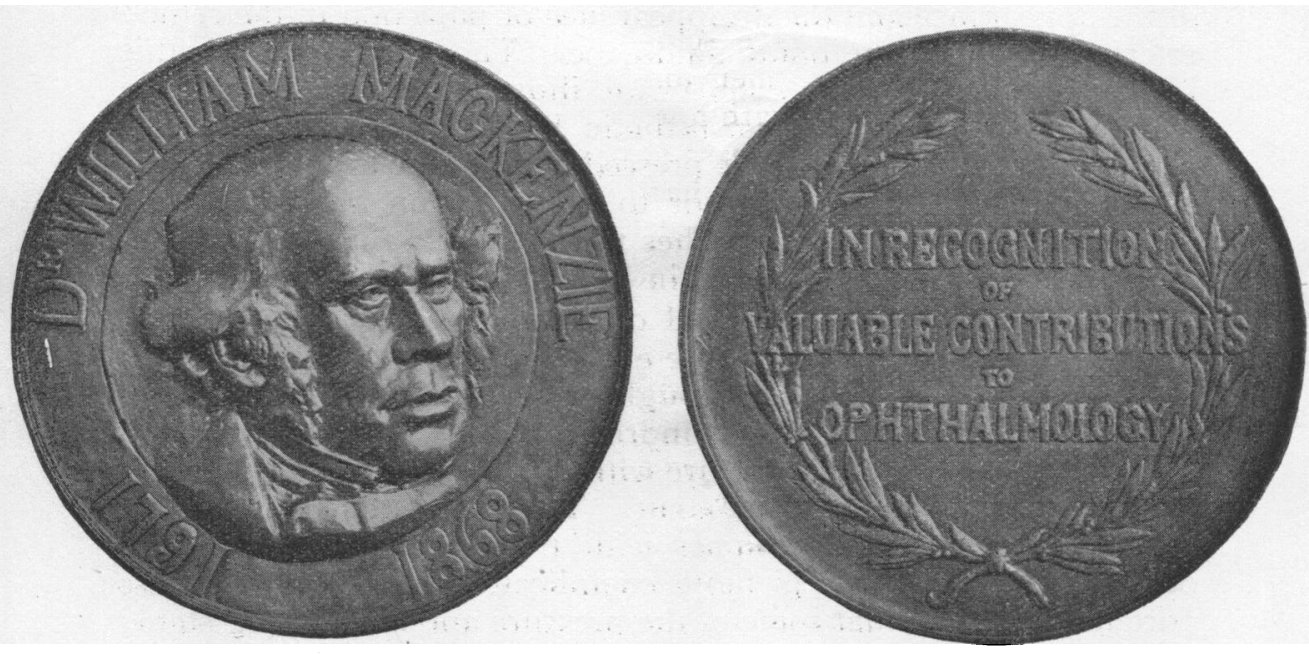

The William Mackenzie Medal.

staff of the Glasgow Eye Infirmary, and the lectureship on "Diseases of the Eye" at the University.

At a meeting held at the Eye Infirmary on the evening of October 9, Dr. Ramsay received the Medal from the hands of Mr. James Gilchrist as representing the custodians of the Memorial Fund. After expressing his appreciation of the honour which had been conferred on him and having paid tribute to Mackenzie and his services to ophthalmology, Dr. Ramsay spoke on the "Importance of General Methods in the Treatment of Eye Diseases." The theme was well suited to the speaker, who has in an eminent degree made it the guiding principle of his practice and an important part of his clinical teaching.

A vote of thanks was accorded to the lecturer on the motion of Sir Donald MacAlister, Principal of Glasgow University. 